\title{
Erken Döneme Ait Bir Fiten Metni*
}

\author{
MICHAEL COOK \\ CEVVIREN: M. EMIN EREN - MUZAFFER TAN \\ ARŞ. GÖR. - DR., ANKARA Ü. İLAHIYAT FAKÜLTESI
}

Nuaym b. Hammâd'ın (ö. 228/ 843) Kitâbu'l-Fiten'i diğer kaynaklarda yer alan erken dönem fiten rivayetlerin** hiçbirine uymayan zengin bir içeriğe sahiptir. ${ }^{1}$ Bu rivayetlerden birisi, diğer rivayetlerden tamamen farklıdır ve bu çalışmanın konusunu da, söz konusu bu istisnai rivayet oluşturmaktadir. ${ }^{2}$

Kitâbu'l-Fiten ve fiten rivayetlerini içeren diğer erken dönem kaynaklarda yer alan çoğu rivayet birkaç satırı geçmemektedir. Söz konusu rivayet, geleceğin kapsamlı bir fotoğrafını sunmaktan ziyade, toplumun gelecekteki tarihinde belirli bir konu, vakıa ya da şahsiyetten bahseden tipik bir rivayettir. Hadislerde olduğu gibi, genellikle, bu tür fiten rivayetler Peygambere veya ondan sonraki erken dönem Müslüman otoritelere dayand1rilmaktadır.

Bu yüzden, erken dönem fiten rivayetleri, aynı dönemin Yahudi, ${ }^{3}$ Hıristiyan $^{4}$ veya daha önceki gayr-i Müslim apokaliptiklerden oldukça farklı

* Metinde birçok yerde geçen "Islamic/Muslim eschatological” şeklindeki ibare, Hadis literatüründeki kullanım dikkate alınarak "fiten” şeklinde çevrilmiştir. (Çev.)

1 Temelde söz konusu eserin malzemesine dayanan yeni bir çalışma için bkz. W. Madelung, "Apocalyptic Prophecies in hims in the Umayyad Age", Journal of Semitic Studies, 31 (1986): 141-85. Fiten'in bir edisyonu Lawrence I. Conrad tarafından hazırlanmış, fakat henüz yayınlanmamıştır.

2 Bu rivayet, Nu'aym b. Hammâd, Kitâbu'l-Fiten, MS British Library, Or. 9449, vr. 198b:9200b:4'te yer almaktadır. Bundan sonra bu çalışmayı Fiten olarak zikredeceğim.

3 İslam'ın erken dönemine ait iki Yahudi apokaliptik rivayet (ya da bundan dolayı fragmanlar) İbranîce Nistarot R. Shim'on ben Yohay'in önemli bir parçasını teşkil etmektedir; metin için bkz. A. Jellinek, Bet ha-Midrasch (Leipzig ve Vienna, 1853- 77), vol. 3, s. 79:9- 80:3, 81:13- 82: 1; çevirisi için bkz. B. Lewis, "An Apocalyptic Vision of Islamic History", Bulletin of the School of Oriental and African Studies 13 (1950): 308-38, özellikle 324-26, 329-30, șerh için, a.g.e., s. 32728, 330. Diğer örnekler, I. Lèvi tarafından neşredilen İbranice bir fragman ("Une Apocalypse 
karakterdedir. ${ }^{5} \mathrm{Bu}$ apokaliptikler, bazen, "gelecek sigasıyla yazılmış"6 sahih rivayetler mesabesinde olup gelecek hakkında daha kapsamlı bilgiler içermektedir. Aynı zamanda, onlar, fiten hadislerinde başvurulanlara nazaran çok daha eski otoritelere dayandırılırlar.

Burada bizi ilgilendiren metin, bu açılardan Müslüman fiten rivayetlerinden çok Yahudi ve Hıristiyan rivayetlerle daha ortak yönlere sahiptir.

İsnadla başlamamız en iyisi olacaktır. ${ }^{7}$ Hadis yeterince sorunsuz bir isnadla başlamaktadır:

Nu'aym [ibn Hammâd] (ö. 228/843)® Hakem ibn Nâfi' (ö. 222/837)8

( Cerrâh [ ibn Muleyh] (ölüm tarihi bilinmiyor) ${ }^{9}{ }^{\circledR}$ Ertât ibni’l-Muzhir (ö. $163 / 779-80)^{10}$

Nu'aym'ın kendisi hariç, bu ravilerin hepsi Hıms (antik Emesa)'lıdırHıms kaynaklı malzeme yüksek oranda, Fiten'de kendisini göstermektedir. ${ }^{11}$ Ertât meşhur Hımslı bir ravidir ve Nu'aym ondan sıklıkla nakillerde bulunur. ${ }^{12}$ Bu noktadan sonra isnad biraz muğlaklık arz eder:

judéo-arabe", Revue des études juives 67 [1914]: 178-82) ile İbranice harflerle Farsça önemli bir parça Qissa-i Daniel (metin ve J. Darmesteter tarafından çevirisi, "L’Apocalypse persane de Daniel", Ecole Pratique des Hautes Etudes içinde, Mélanges [Léon] Renier [Paris, 1887], s. 405-20.

4 Hristiyan cenahta, bu türün örnekleri Kıptî-Arapça Daniel apokaliptikleridir (bkz. C. H. Becker, "Das Reich der Ismaeliten im koptischen Danielbuch", Nachrichten von der Königlichen Gesllschaft der Wissenschaften zu Göttingen içinde, Philologisch-historsche K1. [Berlin 1916], s. 7-57, özellikle 12-16), ve Hristian Bahira efsanesine nüfuz eden daha küçük boyuttaki apokaliptik malzeme için ( Özellikle R. Gottheil'in Arapça çevirisine bkz. "A Christian Bahira Legend", Zeitschrift für Assyriologie [ZA] 13-17 [1898- 1903], özellikle 15 [1900]; apokaliptiğin tarihi için bkz. A. Abel, "L'Apocalypse de Bahîra", Annuaire de l'Institut de Philologie ed d'Historie Orientales 3 [1935]: 1-12, özellikle 7-9).

5 Bu tür, Yahudi ve Hristiyan apokaliptiklerinden daha eskidir. Bkz. H. Hunger ve S. A. Kaufman, "A New Akkadian Prophecy Text", Journal of the American Oriental Society 95 (1975): 371 75, Nebuchadnezzar ya da halefinin iktidarı dönemine ait benzer bir metin; A. K. Grayson, Babylonian Historical Literary Texts (Toronto 1975), s. 13-37 (M. Ö. 12. Asırdaki benzerleri hakkında kısa bir tartışma ile birlikte, a.g.e., s. 16); ayrıca, çok yakında bana bir kopyasını gönderme lütfunde bulunan A. K. Grayson, "The Babylonian Origin of Apocalyptic Literature", Atti dell'Istituto Veneto di Sicienze, Lettere ed Arti, Classe di scienze morali, lettere ed arti 148 (1989-90): 203-18.

6 P. J. Alexander, "Medieval Apocalypses as Historical Sources", The American Historical Review, 73 (1968): 997- 1018, özellikle 1018.

7 Fiten, vr. 198b:9.[el-Fiten, thk. Semîr Emin ez-Zuhayrî, Kahire 1412, II/705, no: 1991 (çev.)]

8 İbn Hacer (ö.852/1449), Tehzîbu't-Tehzîb (Haydarabad 1325-27), II/ 441-43.

9 a.g.e., II/68.

10 a.g.e., I/198.

11 Bunun için bkz. Madelung, "Apocalyptic Prophecies in Hims", s. 143. Madelung ortaya konduğu gibi, Hıms kaynaklı fiten rivayetleri, nüfusunu ağırlıklı olarak Güney Arabistan kökenlilerin oluşturduğu Hıms şehrinin askeri ve dini bir merkez olarak İslam'ın erken dönemlerindeki rolünü yansitmaktadır.

12 Mesela bkz. "The Sufyani between Tradition and History", Studia Islamica 63 (1984): 5-48, özellikle 20-21. 
Bize ulaştı ki (belağanâ) Nâs bir peygamberdi.

Muhtemelen bu Nâs, (ileride göreceğimiz üzere, İsâ'dan önce yaşamış) kadim İsrail peygamberlerinden biri olarak anlaşılmalıdır, fakat (yazma nüshada açıkça işaret edilen) isim bana bir şey ifade etmemektedir. ${ }^{13}$

O halde metin, gerçek anlamda Nâs tarafından ortaya konmuş birtakım biçimsel kronolojik kavramlara dair bir rivayetle başlar: ${ }^{14}$

Zamandan bahsederek dedi ki: "Zaman yedi haftadır, bir hafta (sâbû') yedi bin yuldır ve bir 'asır' ('iddân) ${ }^{15}$ bin yıldır."

$\mathrm{Bu}$ yanlış nakledilmiş görünmektedir; ${ }^{16}$ müteakip metinde, bir 'hafta' yedi bin değil yedi yıldır. Fakat ilginç olan, bunların erken dönem fiten literatürüne yabancı kavramlar olduklarıdır. ${ }^{17}$ Esasında bu kavramlar, Yahudi ve Hıristiyan apokaliptik literatürdeki benzer kavramların acemice Arapçalaştırılmış versiyonlarıdır. ${ }^{18}$

13 Bağlam itibariyle Daniel'i ifade ettiği söylenebilir, zira o, erken dönem İslami literatürde eskatolojide meşhur bir otoriteydi (bkz. M. J. Kister, "Haddithu 'an beni isra'ila wa-la haraja: A Study of an Early Tradition”, Israel Oriental Studies 2 (1972): 215-39, özellikle 235-36).

14 Fiten, vrk. 198b:10

15 Yazma nüshada ilk sesli harf fetha (üstün) olarak harekelenmiştir.

16 Muhtemelen Nâs'ın söylemek istediği bu dünyanın (el-dehr) ömrünün tekbir "mega-hafta" yani, yedinin, her biri asırlarla ayrılmış birer bin yıl olan "mega-günler" ('iddânât) olduğudur. $\mathrm{Bu}$, bir dünya için makul bir ömrü ifade etmekte ve aynı zamanda birkaç satır aşağıda yer alan İsa'nın doğum tarihini anlamlı kılmaktadır.

17 Fiten'in başka bir yerinde veya aşağıda 39. dipnotta işaret edilenin haricinde, diğer erken dönem eskatolojik rivayetlerde onlarla [bu mefhumlarla] karşılaşmadım. A. J. Wensinck ve diğerlerinin, Concordance et indices de la tradition musulmane (Leiden 1936-88) isimli eserlerinde de bunlara bir_sşaret yoktur."zaman" anlamında 'İddân (ya da "addân) terimi sözlüklerde görülmektedir (bkz. E. W. Lane, An Arabic- English Lexicon [London 1863- 93], s. 1971c) ve Arapça'da deyimsel kullanımları yer almaktadır; 'adân kalıbında yedi yıl anlamında verilmektedir (a.g.e., s. 1976c; ayrıca, Ezherî (ö. 370/980-81), Tehzîbu’l-Luğa, thk. A. M. Harun ve diğerleri, [Kahire 1964-67], cilt 12, s. 220a:3, Mufaddal [ed-Dabbî]'den [ö. 170/ 786-87] naklen). Bununla birlikte, öyle görünüyor ki sâbû' terimi lügatçilerce bilinmemektedir.

18 'İddân kavramı Daniel Kitabı'nda zaten önemli bir yere sahiptir; basitçe 'zaman' anlamına gelmediği yerlerde, tek bir yıl anlamına gelmektedir (bkz. F. Brown ve diğerleri, A Hebrew and English Lexicon of Old Testament [Oxford, 1906], s. 1105b). Yedi ylllı bir süre olarak 'hafta' (shabu'a) Yahudi kullanımında iyi bilinir (M. Jastrow, A Dictionary of the Targumim, the Talmud Babli and Yerushalmi, and the Midrashic Literature [London 1903], s. 1105b, shâbû'a maddesi) ve Nistârot R. Shim'ôn ben Yôhay (Jellinek, Bet ha-Midrasch, vol. 3, s. 82:1)'da yer almaktadır. Hıristiyan tarafında ise dikkat çekici bir şekilde, yedinci asırda Methodius'a atfedilen apokaliptikte şekillenmektedir (örneğin bkz. F. J. Martinez edisyonu, "Eastern Christian Apocalyptic in the Early Muslim Period: Pseudo-Methodius an Pseudo-Athanasius" [Doktora tezi, Catholic University of America, 1985], s. 66:55= 130). Keza, İslam tarihinin (erken dönemine ait ?) Süryanice bir metin olan Ezra'nın Apokaliptiğinde (J. -B. Chabot, "L'Apocalypse d'Esdras", Recue Sémitique 2 [1894]: 242-50, 333-46, özellikle 248:10= 338, §54; tarihlendirme için krş. Ag.e., s.345) ve Süryanice Bahîrâ efsanesinde (Gottheil, "A Christian Bahira Legend" ZA 13 [1898]: 189-242, özellikle, 211:18, 229:21, 237:21) görülmektedir. Hıristiyan Arapçası'nda, bu terime yine, Bahira efsanesine dair apokaliptik metinlerde rastlanır (ZA 14 [1899]: 203-68, özellikle 261:4, 264:13; ZA 15 [1900]: 81:4, 88:3). 
Sonra, Nâs'ın olayların müstakbel seyri hakkındaki anlatımı devam eder. Geçmiş nesilleri anlattıktan sonra (ayrıntılar dışarıda tutuluyor), Nâs, İsa'nın doğuşunun "son haftanın dört devrinin bitişinde" 19 olacağ 1 kehanetinde bulunuyor. Şayet bu bağlamda bir "hafta" bin yıl ve bir "devir (epoch)" de bir asırsa, bu durumda İsa'nın doğumu M.S. 6400'e tekabül etmektedir. ${ }^{20}$ Müteakiben, fırkaların (ehvâ) artmasıyla birlikte, Muhammed'in gelişi yeterince kapalı, fakat oldukça kesin ifadelerle haber verilir. ${ }^{21} \mathrm{O}$, İran, Afrika ve Suriye'ye ${ }^{22}$ hâkim olacak ve "haftanın yedide biri eksik, üç hafta sonra" ölecektir; burada bir "hafta" yedi yıl olmalıdır. Bu şekilde peygambere anormal uzunlukta yirmi yıllık bir hükümranlık vermektedir.

Devamında gelenler aslında, tarihsel bir olaydır. Müslüman hükümdarlar birer birer önceden verilmiştir ve her birinin iktidar süresi "haftalar"la belirtilmiştir; hiç birinin ismi verilmese de zikredilenlerin tamamını tespit etmek rahatlıkla mümkündür. Neticede, halife Ömer (13-23/634-44) de bu şekilde işaret edilmektedir: ${ }^{23}$

Ve ondan [Ebu Bekir] sonra güçlü ve adil bir adam yönetecek ve Suriye (el-Şâm) fethedilecek; onun kaybı bir felaket (musibet) olacak; hayatı, bir haftanın üçte ikisi eksik, bir haftanın yarısı kadardır. ${ }^{24}$

Sonraki idarecilerle ilgili ifadelerde dikkati çeken iki husus vardır. Birisi, hilafetin, on üç yıl iktidarda kalan Osman'dan tam olarak yirmi bir yıl iktidarda kalan Muaviye'ye geçmesidir. Bu hususta Ali'ye herhangi bir atfın olmaması, ${ }^{25}$ (Irak kaynağının aksine) daha önce belirtilen Hıms isnatlı metnin $^{26}$ Suriye kaynağına uymaktadır. Dikkat çeken diğer bir husus II. Yezid (101-5/720-24) ile ilgili ifadedir ${ }^{27}$ :

19 Fiten, vrk. 198b:12.

$20 \mathrm{Bu}$, dünyanın miladi 600'de sona erdiğini ima etmektedir. Ĕ̆ger öyleyse, vahyin Ertât'ın yetiştiği dönemin, en azından, hemen öncesine kadar devam etmiş olması gerekir.

21 A.g.e., vrk. 198b:14.

$22 \mathrm{Bu}$ form tekrar ortaya çıkar (a.g.e., vrk. 199a:3, 200a:18).

23 A.g.e., vrk. 198b:19.

24 Ona verilen hükümranlık süresi -sekiz yıl ve iki ay- oldukça kısadır. Nisf sâbû‘ yerine nisf sub` $s a \hat{b} \hat{u}^{\prime}$ olarak okunması bir parça daha uzun bir sonuç verir.

25 “Onun [Osman'ın] katili hâkim olamayacak” (a.g.e., vrk. 198b:20) ifadesiyle o [Ali] kastedilmemişse.

26 Bkz. P. Crone, Slaves on Horses: The Evolution of the Islamic Polity (Cambridge 1980), s. 204, n. 30. Hımslıların, hemşehrileri İsmail b. Ayyâş (ö.181/ 797) Ali'nin faziletlerini onlara anlatmaya başlayıncaya kadar, Ali hakkında olumsuz bir kanaate sahip oldukları rivayet edilir (mesela bkz. İbn Hacer, Tehzib, I, s. 322:13 ve VIII, s. 464:1; Madelung, "The Sufyani”, s.17 ve G. H. A. Juynboll, Muslim Tradition [Cambridge 1983], s. 5, 10. dipnottan naklen).

27 Fiten, vrk. 199a:10. 
Ondan [Ömer b. Abdülaziz] sonra kendisiyle böbürlenen (es-Sâlif), ${ }^{28}$ binaları yıkan (hâdimu'l-Bunyân) ve resimleri tahrip eden (muğayyiru'ssuvar) iktidara geçecek; onun hayatı üç haftadan bir haftanın üçte ikisi kadar az olacaktır. ${ }^{29}$

Yezid'in ikonoklazm'ına* yapılan atfı ilginç kılan husus, Müslüman bir endişeden ziyade Hıristiyan bir endişe taşıdığ 1 izlenimi vermesidir. ${ }^{30}$

Emevi Hükümdarlarıyla ilgili bu tarihsel bilgiler, iktidarı altı yıl süren II. Mervan (127-32/ 744-50) iktidarıyla sonlandırılmaktadır. ${ }^{31}$ Sonra, Abbasî ihtilâli ("doğu rüzgarı"), Suriye'nin fethi ve yirmi beş yıl sekiz ay süren Abbasi iktidarı gelir. ${ }^{32}$ Bununla birlikte, şimdiye dek bu rivayet tarihsel karakterini kaybetmiş görünmektedir. Abbasi halifeler silsilesine dair net bir ifade bulunmamaktadır ${ }^{33}$ ve olaylar gittikçe muğlaklaşmaktadır. Bu rivayetin bir parçası olduğu anlaşılan son pasaj birdenbire bütünü vermektedir: "Suriye'nin Kureyş tarafından fethinden itibaren yirmi bir hafta, yani 147 yıl." 34

Bu toplam süre, bu dönemdeki Müslüman hükümdarların iktidardaki toplam süreleriyle karşılaştırıldığında, rivayetin, metindeki tahrif ve ihmallerden ötürü, yaklaşık on yedi yıl eksik olduğu anlaşılmaktadır. Daha önemlisi, bu rakamlar bize, söz konusu rivayetin yaklaşık olarak ortaya çıkış tarihini de vermektedir. Abbasi iktidarının yirmi beş yıl sekiz ayı bizi, Mansûr'

28 Sözlüklerde, bu anlam üzerinde bir ittifak yoktur (krş. Lane, Lexicon, s.1718c); ancak söz konusu ifade açık bir şekilde aşağılayıcıdır.

29 Bu uzun hükümranlık, muhtemelen metindeki bir boşluğun neticesi olarak belirtilmeyen Hişâm (105-25/724-43) olabilir. Yine de bu, onun için oldukça kısa bir süredir. "Bina"dan neyin kastedildiğini bilmiyorum.

* Iconoclasm: Yerleşmiş inanç, gelenek veya kurumlara karşı çıkma; ikonoklazm, ikon kırıcılık [Çev.]

30 (Hıristiyanlığın aksine) Müslüman kaynaklarda bu tarz bir ölçüme atıfta bulunmanın nadir oluşuyla alakalı olarak bkz. A. A. Vasiliev, "The Iconoclastic Edict of The Caliph Yazid II, A.D. 721", Dumbarton Oaks Papers 9-10 (1956): 23-47, özellikle, 39-40. Ayrıca, Daniel'in Kıpti harflerle yazılmış Arap apokaliptiğindeki Yezid ikonoklazm'ına yapılan atıflarla karşılaştır (Becker, "Das Reich der Ismaeliten im koptischen Danielbuch", p. 13 paragraf 25=19, şerh, s. 25; Becker bu hükümdarı II. Ömer ile özdeşleştirmeye çalışır [a.g.m., s. 31-32], fakat müteakip paragrafta onun iktidarı kırk ay olarak belirtildiğinden Yezid olması daha uygundur).

31 Fiten, vr. 199a:13.

32 A.g.e., vr. 199a:14

33 İlk iki Abbasi halifesi olması muhtemel, aynı ismi taşıyan iki şahsa atıf vardır ( el-Saffâh ve elMansûr'un her ikisi Abdullah ismi taşımaktadır; bkz. İbn Hazm (ö. 456/1064), Cemheratu Ansâbi'l-'Arab, thk. A. M. Harûn, Kahire 1982, s. 20:10). Bununla birlikte, ikinci şahsın savaşta öldüğü anlaşılmaktadır ve bu durum, Suriye'de Abbasi iktidarının tesisinde anahtar rol oynayan amcaları Abdullah b. Ali olması ihtimaliyle daha uygun düşmektedir.

34 Fiten, vr. 199a:21. 147 yıl rakamı, makul olmayan bir bağlamda, Daniel'in Kıpti-Arapça apokaliptiğinde göze çarpmaktadır (Becker, "Das Reich der Ismailiten im Koptischen Danielbuch", s. 13, paragraf $29=19$, şerh, s. 25 
un 158/775'teki ölümüne götürürken; ${ }^{35}$ Müslümanların Suriye'yi fethinden itibaren 147 yıl bizi, 167/783 yılına götürür. ${ }^{36}$ Hicri 160'lı yılların sonu, miladi 780'li yılların başlarındaki bir tarihlendirme doğru görünmektedir.

Her ne kadar hadisin metni burada bitmiyor olsa da, şimdiye kadar rivayette sağlam bir kronolojik yapı ve net tarihsel referanslar aramamız bir netice vermemiştir. Üslup, Abbasilerin ilk dönemine ilişkin muğlak bir imayla devam etmekte ve bu döneme ait bazı temalar tekrarlanmaktadır. "Boğa" (es-sevr) ${ }^{37}$ olarak zikredilen şahsın rolü, Harran'ın "putlar şehri" (medinetu'l-Asnâm) ${ }^{38}$ olarak ima edilmesi gibi. "Hafta" terminolojisi nadiren de olsa kullanılmaya devam etmektedir. ${ }^{39}$ Aynı zamanda, konuların asıl fiten hadisinden tasvir edilişleri de kayda değerdir. ${ }^{40}$ Bununla birlikte metin, hâlâ çok sayıda olağandışı hususu içermektedir. ${ }^{41}$

Rivayetin apokaliptik tarihi bilgi olarak ifade ettiğim kısmının kaynağı nedir? Sahip olduğumuz haliyle elimizdeki metin, açıça, bir Müslüman belgesidir. Ne Yahudi apokaliptik bir metin İsa'yı, ne de Hiristiyan bir metin İslam Peygamberini tasdik eder. Aynı şekilde metnin dili Arapça'dır ve Kur'an terminolojisinin sarih örnekleri (dehr, ehvâ gibi) vardır. ${ }^{42}$

$35 \mathrm{Bu}$ yılların güneşe göre hesaplandığını varsayarsak, en uygun sonucu elde ederiz.

36 Suriye'nin fethedildiği tarihi 15/636 olarak alıyorum ve yılların güneş yılı olduğunu varsayıyorum.

37 Örneğin bkz. Fiten, vrk. 199a:15, 199b:8. Daha erken bir eskatolojik boğa, Kadın Peygamberin On üçüncü Kehaneti'nde [Thirteenth Sibylline Oracle] bulunur (bkz. D. S. Potter, Prophecy and History in the Crisis of Roman Empire [Oxford 1990], s. 176:158, çevirisi, s. 177, şerhi, s. 151, 329; bu çalışma Peter Brown tarafından dikkatime sunulmuştur). Yaklaşık olarak birbirleriyle muasır olanlar, Süryanice Ezra apokaliptiklerinde (Chabot, "L'Apocalypse d'Esdras", $245: 17=336, \S 26 ; 247: 11$ ve dipnot $2=337, \S 42$ ) ve Bahira Efsanesine dair apokaliptik malzemede (Gottheil, "A Christian Bahira Legend", ZA, 13 (1898): 205:12, 205:24 (Süryanice); ZA 14 (1899): 255:4 (Arapça) göze çarpmaktadır. Genel olarak, eskatolojik hayvan șeklinde simgeleștirme geleneği için bkz. Potter, Prophecy and History, s. 226-27.

38 Fiten, vrk. 199a:19, 199b:8. Bundan sonra şehre ismiyle atıfta bulunulur.

39 A.g.e., vrk. 199b:10, 199b:11, 200a:6, 200b:1.

40 Böylece, A’mâq'a ulaşan Bizans saldırılarına (a.g.e., vr. 199b:19), Yemenli kurtarıcıya (a.g.e., vr. 200a: 1), Endülüs hükümdarlarının gelişine (a.g.e., vr. 200a: 8) ve Bizanslılarla karşılaşmada Mevâlînin rolüne dair bilgi sahibi oluyoruz. Bu temalar için örneğin bkz. Madelung, "Apocalyptic Prophecies in Hims", s. 149-58 (Yemenli kurtarıcı hakkında), 158 (A’mâq hakkında), 161-62 ( mevâlînin rolü hakkında) ; J. Aguadé, "Algunos hadices sobre la acupación de Alejandría por un grupo de hispano-musulmanes", Boletín de la Asociación Española de Orientalistas 12 (1976): 159-80, G ve H versiyonları (Endülüs Hükümdarı içindir).

$41 \mathrm{Bu}$ şekilde Frenklere (Ifrenc, a.g.e., vr. 200a:1) ve İspanyollara atıflar yer alır (Barbar ve Ifranc ve'l-Aşbâl sıralamasındaki el-Eşbâl ibaresi İşbâl şeklinde okunmalıdır, a.g.e., vr. 200a: 9). Ard Suriye kelimesi, burada, muhtemelen Isauria anlamındadır (a.g.e., vr. 200a: 18). Constantinople [ İstanbul]'a Buzantiya şeklinde atıfta bulunulur (a.y.). Ard Suriye ve Buzantiya, her ikisi, Artât'tan nakledilen bir rivayetin benzer pasajında tekrarlanır (a.g.e., vr. 122a: 11).

42 Buna benzer bir başka örnek Peygambere ilişkin ifadedir: Men saddekahû âmene ve man cehedehû kefera (a.g.e., vr. 198b:16). 
Bununla birlikte, Müslüman hadisçilerin dünyası dışına işarette bulunan pek çok husus vardır. Kronolojiye dair terminoloji açık bir şekilde gayri Müslim bir kaynaktan ödünç alınmıştır. Tarihlendirmenin, Hicret'in aksine Suriye'nin fethine göre olması da gayr-i İslamî'dir. Arapça, acemice olup Arapça dil kurallarına aykırıdır. ${ }^{43}$ Yezid ikonoklazmına yapılan atıf Hıristiyan bir arka planı akla getirmektedir. Her şeyden önce, üslubun bütünü ilk Müslüman fiten literatürüne yabancı olup daha çok gayr-1 müslim bir ortama aittir. ${ }^{44}$

Bu yüzden, burada elimizde olan metnin, Abbasilerin ilk dönemine ait gayr-i Müslim, muhtemelen Hıristiyan, Süryani bir apokaliptiğin tercümesi ile yeniden yazımı arasında bir şey olduğu kanaatindeyim. Arapça'ya çevrilmiş Hıristiyan bir metin olarak, erken bir rivayettir; muhaddislerin literatüründe yer bulmuş haliyle ise bildiğim kadarıyla tek örnektir. Bu geçişin gerçekleştiği gayr-i resmi kültürel etkileşim süreci hakkında sadece spekülasyonda bulunabiliriz. ${ }^{45}$

43 Örneğin, 41 ve öncesi alıntılara bkz.

44 Aynı döneme ilişkin bir benzer bir durum için bkz. H. Usener, "De Stephano Alexandrino," onun Kleine Schriften isimli eserinin içinde (Leipzing, 1912-14), vol. 3, s. 279-86. Bu Yunan astrolojik metin, tarihsel olarak, el-Mansur'un iktidarından önceki yirmi dört Arap hükümdar hakkında kehanette bulunur; Usener onu, 158-59/ 775 olarak tarihlendirir (Onun tahlili için bkz. a.g.e., s. 259,261$)$.

45 II/VIII. asır Müslümanlarının Hıristiyan apokaliptik literatürün cazibesinde kalmadıkları, Suriyeli Michael (ö. 596/1199)'in aktardı̆̆ı dikkat çekici rivayetinde dile getirilmiştir. (J.B. Chabot, ed. Chronique de Michel el Syrien [Paris 1899-1910] Becker tarafından zikredilmiştir, "Das Reich der Ismaeliten im koptischen Danielbuch", s. 53). Sicistan'nn Monofizit Piskoposu, dini gerekçelerden ötürü Mervan'a yaltaklanmış, bu amaçla o ve işbirlikçisi " Apocalypse of Enoch" adını verdikleri bir eser kaleme almışlardır. Bu eserin bir yerine Mervan'ın ve ondan sonra oğlunun iktidara geleceğini belirten bir ibare yerleştirmişlerdir. Mervan bu hileyi fark eder ve onlara bu metinle ilgili bir şerh hazırlatır. Doğal olarak kendisinden sonra oğlu iktidara gelmemiştir. 